\title{
Histopathologic Features of Lymphedema: A Molecular Review
}

\author{
Claire Y. Li®, Raghu P. Kataru and Babak J. Mehrara *
}

The Department of Surgery, Division of Plastic and Reconstructive Surgery, Memorial Sloan Kettering Cancer Center, New York, NY 10065, USA; lic2@mskcc.org (C.Y.L.); katarur@mskcc.org (R.P.K.)

* Correspondence: mehrarab@mskcc.org; Tel.: +01-212-639-8639; Fax: +01-212-717-3677

Received: 13 March 2020; Accepted: 2 April 2020; Published: 6 April 2020

\begin{abstract}
An estimated 5 million people in the United States are affected by secondary lymphedema, with most cases attributed to malignancies or malignancy-related treatments. The pathogenesis of secondary lymphedema has historically been attributed to lymphatic injury or dysfunction; however, recent studies illustrate the complexity of lymphedema as a disease process in which many of its clinical features such as inflammation, fibrosis, adipogenesis, and recurrent infections contribute to on-going lymphatic dysfunction in a vicious cycle. Investigations into the molecular underpinning of these features further our understanding of the pathophysiology of this disease and suggests new therapeutics.
\end{abstract}

Keywords: lymphedema; inflammatory skin conditions; inflammation; immunity; fibrosis; adipogenesis; recurrent infections

\section{Introduction}

Lymphedema is a progressive and morbid disease characterized by swelling and fibrosis of the affected region resulting in functional problems, decreased quality of life, and recurrent infections. The underlying pathogenesis of lymphedema involves dysfunction in lymphatic transport, which under normal conditions is responsible for transporting residual interstitial fluid, immune cells, and lipids. Lymphedema can be further classified into primary and secondary lymphedema. Primary lymphedema is caused by a congenital dysfunction of the lymphatic system; in contrast, secondary lymphedema results from disease or iatrogenic processes. Secondary lymphedema is significantly more common and usually related to cancer treatments. Breast cancer-related lymphedema accounts for most cases of secondary lymphedema in the United States due to the high incidence of breast cancer [1]. Estimates of the risk of lymphedema following lymph node dissection for breast cancer vary and depend on the length of follow-up ranging between $16 \%$ and $60 \%$ [2,3]. The advent of sentinel lymph node sampling for breast cancer and other malignancies has drastically reduced the need for lymph node dissection; however, even sentinel lymph node biopsies involve a clinically relevant risk of lymphedema [2,4-7]. In addition to lymph node dissection, extensive skin resections, radiation therapy, obesity, and infections have also been identified as significant risk factors for disease development $[4,8,9]$. Lymphedema is also commonly seen in patients treated for other solid tumors, with reported incidence in melanoma of $16 \%$, sarcoma $30 \%$, gynecologic tumors $20 \%$, genitourinary tumors 10\%, and head and neck cancers $4 \%$ [10]. Given that the incidence of lymphedema is directly correlated with survival time after cancer therapy, the prevalence of this disease will increase as life expectancy in cancer survivors is improved with better treatments [11]. With 5 million Americans currently estimated to be suffering from this condition, lymphedema represents a great biomedical burden [11]. 
Currently, there is no cure or effective treatment for the management of lymphedema; the mainstay of therapy is palliative, aiming to prevent disease progression and to provide symptomatic improvements. These therapies consist of a multimodal approach known as complete decongestive therapy (CDT) and involves four components: compression therapy, manual lymphatic drainage, exercise, and skin care [12-16]. These palliative therapies are helpful in most patients [12,17]. However, compression therapy is usually required continuously and is a significant source of dissatisfaction among patients. Manual lymphatic drainage and physical therapy is also time consuming and expensive. This is particularly problematic since these costs are often not covered by medical insurance. Thus, developing novel therapies that resolve the underlying problem rather than simply provide symptomatic relief are an important unmet clinical need.

More recently, surgical treatments for lymphedema such as lymphovenous bypass, vascularized lymph node transplant, and reductive techniques, including liposuction and direct excision, have been developed with varying degrees of success $[18,19]$. Although lymphatic surgery has proven to be helpful in some cases, these procedures inexplicably fail to improve outcomes in others, likely reflecting the complex pathophysiology of the disease [19,20]. Therefore, a greater understanding of the pathophysiology of this disease is needed to develop effective therapies. This review aims to summarize the clinical and pathologic features of secondary lymphedema and to review our present understanding regarding the molecular basis of these findings.

\section{Clinical Presentation and Staging}

The natural history of secondary lymphedema is highly variable with disease progression ranging from latent in some patients to rapidly progressive in others. Disease onset is usually insidious and delayed. Breast cancer-related lymphedema develops, on average, eight months following surgery, with $80 \%$ of patients diagnosed in the first three years after surgery [4]. The development of lower-extremity lymphedema following pelvic or inguinal lymph node dissection is more rapid, with most cases occurring 3-6 months after surgery [21,22]. Initially, affected patients may report the sensation of swelling or heaviness of the affected limb. These symptoms may lead to the development of pitting edema manifesting as an indentation in the skin after firm pressure is applied for several seconds and released. With disease progression, the skin becomes dry and firm with decreasing pitting secondary to cutaneous fibrosis and adipose deposition. The Kaposi-Stemmer sign, in which the examiner is unable to pinch the skin fold at the base of the second toe on the dorsal aspect of the foot or the webspace of the hand, is considered to be indicative of lymphedema. However, the absence of this sign is not diagnostic since in some patients with extremity lymphedema, the hands or feet are spared from swelling. Dermal thickening becomes clinically apparent at later stages of the disease and progresses to hyperkeratosis, acanthosis, lichenification, and verrucae [23]. The overlying skin may appear "cobblestoned" in appearance and is prone to fissures and recurrent infections, a hallmark of lymphedema [23]. Cellulitis, erysipelas, tinea pedis, and lymphangitis have all been associated with chronic lymphedema [23]. In very rare instances, patients with long-standing lymphedema ( $\geq 10$ years) are at risk of developing an aggressive form of cutaneous angiosarcoma known as Stewart-Treves syndrome [24]. There are various classification systems used to describe disease severity, although the International Society of Lymphology (ISL) stage is the most widely used. ISL staging combines "softness" and effect of limb volume after elevation into stages 0-III. Stage 0 describes subclinical lymphedema where swelling is not evident despite impaired lymphatic transport, although patients may report a feeling of heaviness in the limb. Stage I lymphedema corresponds to limb swelling that resides with elevation or compression, usually within 24 hours. Pitting may be evident at this stage, although there is a lack of dermal fibrosis. Stage II lymphedema does not subside with elevation or compression, reflecting the consequences of dermal fibrosis. Stage III lymphedema, the most severe stage, is characterized by severe and permanent limb swelling as well as trophic skin changes such as fat deposits, acanthosis, and verrucae [23]. 


\section{Role of Inflammation in Development of Lymphedema}

Initial lymphatic insult results in the chronic accumulation of protein-rich interstitial fluid that promotes inflammation and fibroadipose deposition. If collateral lymphatics are not able to compensate for the initial injury, these pathologic changes exacerbate persistent fluid accumulation, which further impair lymphatic dysfunction in a positive feed-back loop. Attempts to characterize the hallmark inflammatory nature of lymphedema have implicated CD4+ T cells in the inflammatory response leading to lymphedema. Avraham et al. and Zampell et al. showed that in the mouse tail surgery and popliteal lymph node dissection (PLND) models of lymphedema, greater than $70 \%$ of the inflammatory response consisted of CD4+ T cells $[25,26]$. Similar changes were seen in human specimens collected from patients with unilateral upper extremity breast cancer-related lymphedema, where the number of tissue-infiltrating CD4+ T cells was positively correlated with severity of disease (Figure 1) [26]. CD4-deficient mice were protected from developing lymphedema following tail lymphatic ablation; similar findings were noted when $\mathrm{CD} 4+\mathrm{T}$ cells were depleted using neutralizing antibodies in wild-type (WT) mice [26]. This effect was isolated to CD4+ T cells as depletion of macrophages or CD8+ $\mathrm{T}$ cells did not prevent development of lymphedema [26]. Another group reported similar findings in which lymphatic vessel remodeling and collecting vessel impairment was associated with increased number of CD4+ T cells [27]. Ogata et al. found that the interaction between CD4+ T cells, specifically $\mathrm{T}$ helper type 1 and $\mathrm{T}$ helper type 17 cells, and macrophages promotes vascular endothelial growth factor C (VEGF-C) expression, which in turn led to the generation of immature and leaky lymphatic vessels that are essential for the development of initial edema [28].
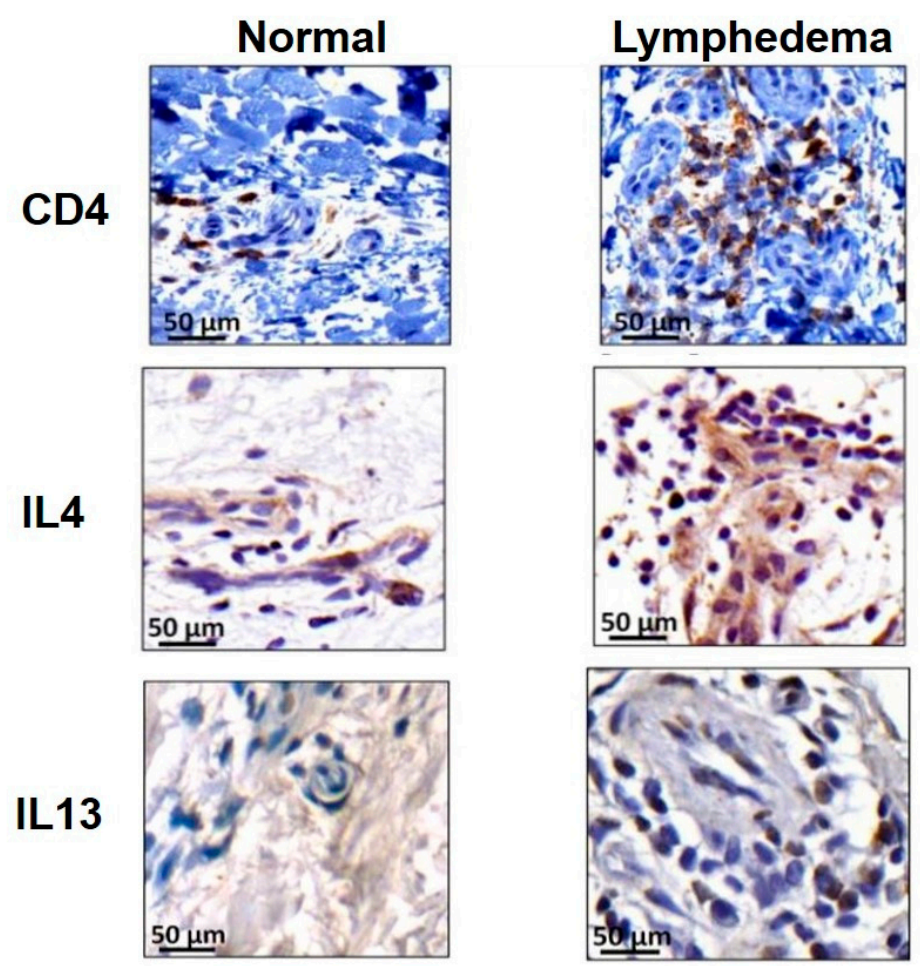

Figure 1. Representative immunohistochemistry images demonstrating CD4+ (upper), IL-4+ (middle), and IL-13+ (lower) cells in matched human biopsy specimens comparing lymphedematous and contralateral normal upper extremities. Reprinted with permission from supplemental figure 1 [26].

Indeed, recent work from our own laboratory indicates $\mathrm{CD} 4+\mathrm{T}$ cell activation is necessary and sufficient for the development of lymphedema [29,30]. Using the tail surgery and PLND models of lymphedema, Garcia Nores et al. found that adoptive transfer of CD4+ T cells to CD4-deficient mice led to the development of lymphedema similar to that seen in WT mice; in contrast, no swelling was seen in CD4-deficient mice that did not undergo adoptive transfer [29]. These authors showed that following tail 
surgery or PLND, CD4+ T cells are released from draining lymph nodes and home to lymphedematous skin, a process dependent on dendritic cell (DC) activation [29]. Once in the skin, CD4+ T cells promote changes such as impaired lymphangiogenesis, fibrosis, and increased inducible nitric oxide synthase (iNOS) expression leading to lymphedema [29]. Increased expression of iNOS results in disruption of the endogenous nitric oxide gradient that regulates intrinsic lymphatic pumping [31,32]. When CD4+ $\mathrm{T}$ cells were sequestered in the lymph node using a sphingosine-1-phosphate receptor modulator, animals did not develop lymphedema [29]. Moreover, using a mouse model of relative CD4+ T-cell deficiency created by reconstituting irradiated WT mice with CD4 knockout mouse-derived bone marrow progenitors, Ly et al. showed that even small numbers of CD4+ T cells are sufficient for the development of lymphedema and its associated histopathologic features [30].

\section{Lymphedema as Fibrotic End-Organ Failure of Lymphatic System}

Fibrosis is a common mode of end-organ failure in a variety of organ systems including the liver, lung, heart, pancreas, and kidney. Similarly, in chronic lymphedema, the collecting vessels become progressively fibrosed and are eventually replaced by scar tissue that obliterates the luminal area of the vessel [33]. In a mouse tail model of lymphedema, treatment with type I collagen gel resulted in downregulation of TGF $\beta-1$ expression and scar formation which in turn accelerated lymphatic regeneration [34]. Collagen gel treated animals were also found to have both decreased soft tissue fibrosis and expression of pro-fibrotic genes by lymphatic endothelial cells (LECs) with concomittant improvements in lymphatic function in the form of increased number of lymphatic vessels, improved lymphatic architecture, and increased proliferation of LECs [35]. These findings suggest lymphedema may represent fibrotic organ failure of the lymphatic system.

Evidence from several studies highlights the importance of T helper cells in the pathogenesis of fibrosis. Notably, a T helper 1 (Th1) and T helper 2 (Th2) paradigm describes profibrotic cytokines and growth factors elaborated by Th 2 cells, including IL-4, IL-13, and transforming growth factor- $\beta 1$ (TGF- $\beta 1$ ), that regulate collagen deposition and fibrosis in various organ systems [36]. For example, adoptively transferred naïve CD4+ T cells differentiated into Th1 and Th2 cells in mice that had undergone PLND [29]. These cells migrated to and proliferated in the hindlimb distal to the zone of lymphatic injury [29]. Furthermore, emerging evidence suggests a crucial role for specifically Th2 cells in the regulation of fibrosis that leads to lymphatic dysfunction [26]. Th2-deficient transgenic mice are protected from developing lymphedema and fibrosis as compared to animals with defective Th1 cell generation [37]. This finding is supported in mouse lymphedema models and human samples from breast cancer-related lymphedema, in which lymphatic injury results in a Th2-biased response with the infiltration of large numbers of CD4+ IL-4+ IL-13+ Th2 cells (Figure 1) [26,38]. Consequently, when these same animals were treated with IL-4 or IL-13 neutralizing antibodies, lymphedema was prevented [26]. The same findings were seen in a mouse asthma model in which blockade of IL-4 and/or IL-13 increased lung lymphatic vessel density and function [39]. Mechanistically, IL-4 and IL-13 downregulate LEC-specific transcription factor Prox-1 and LEC marker LYVE-1 and has been shown to impair LEC survival, proliferation, and tubule migration in vitro and in vivo (Figure 2) [40].

A large body of literature has implicated the TGF- $\beta 1$ pathway as an important mechanistic player in regulating fibrosis in a number of organ systems [36,41]. Indeed, increased levels of TGF- $\beta 1$ were found in lymphedematous tissue of both mice and patients, and TGF- $\beta 1$ blocking antibodies resulted in both decreased fibrosis and improved lymphatic function in animal models [42,43]. The same phenomenon was observed using an animal model with dominant negative TGF- $\beta 1$ receptors [42]. Interestingly, TGF- $\beta 1$ blockade was also associated with decreased Th 2 cell migration and expression of profibrotic Th2 cytokines (Figure 2) [42]. This reciprocal interaction between TGF- $\beta 1$ signaling and Th2 cell response is also consistent with the development of fibrosis in other organ systems [44]. Although the exact mechanism by which fibrosis induces lymphatic dysfunction requires additional clarification, it is likely the result of progressive obliteration of the initial and collecting lymphatic vessels and impaired collateral regeneration [45]. 


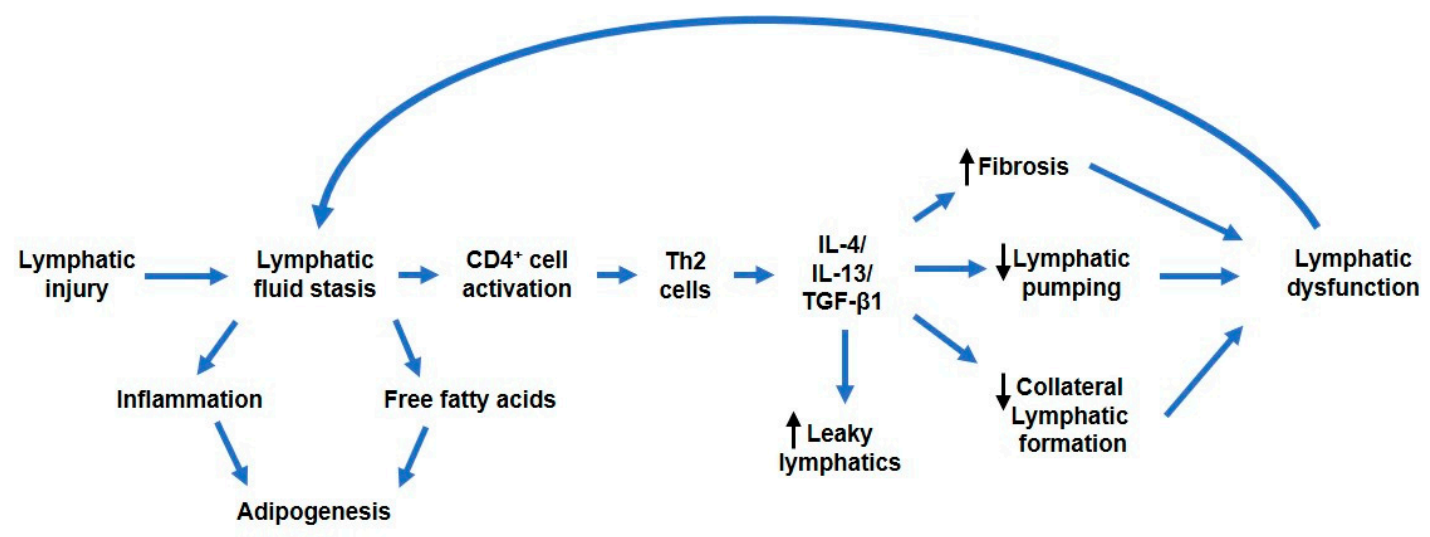

Figure 2. Schematic showing proposed pathophysiologic consequences following initial lymphatic injury. The accumulation of lymphatic fluid incites adipogenesis and an inflammatory response that sets off a cascade of molecular events leading to lymphatic impairment. Notably, of the inflammatory response, CD4+ T cell activation has been shown to be both necessary and sufifficent for the development of lymphedema. CD4+ T cell activation induces elaboration of T helper 2 (Th2) cytokines IL-4 and IL-13, along with transforming growth factor- $\beta 1$ (TGF- $\beta 1$ ), that contribute to lymphatic dysfunction either directly or indirectly by promoting tissue fibrosis, decreasing lymphatic pumping, impairing collateral lymphatic formation, and increasing lymphatic leakiness. The culminative effect is worsening of lymphatic fluid stasis.

\section{Lymphedema Results in Adipose Deposition}

Adipose deposition is a late stage pathologic feature of lymphedema. Several studies provide evidence that lymphatic fluid stasis drives adipose differentiation. Prox-1 is a master regulator of lymphatic development, and Prox-1 knockout mice develop chylothorax and die in utero or shortly after birth [46]. Mice with heterozygous inactivation of Prox-1 survive in some genetic backgrounds and become obese as adults even when fed a normal chow diet [47]. In these animals, fat deposition occurs most abundantly around the abnormal mesenteric lymphatics [48]. More recent studies have shown that fatty acids in lymphatic fluid promote adipocyte proliferation and differentiation, suggesting that lymphatic stasis can directly increase adipose deposition in affected tissues [49]. Consistent with these findings, Zampbell et al. and Aschen et al. found that adipose differentiation markers, including adiponectin and CCAAT/enhancer-binding protein-alpha, are increased following lymphatic injury in a mouse model of lymphedema [50,51]. IL-6, a known regulator of adipose tissue homeostasis, appears to be a negative regulator of adipose deposition in the setting of lymphedema as loss of IL-6 function resulted in increased adipose deposition in the tail surgery model of lymphedema in one study [52]. Interestingly, in the same study, it was shown that IL-6 is increased locally and systemically in patients with lymphedema, which was corroborated in animal models [52]. These data suggest IL-6 plays an important homeostatic role to limit adipose deposition in response to lymphatic injury and inflammation [52].

Given that obesity is a well-recognized risk factor for the development of secondary lymphedema, it is not suprising that on a molecular level, the relationship between lymphatic dysfunction and adipogenesis appears bidirectional [2,53]. In vitro, LECs exposed to long-chain free fatty acids have increased markers of cell death and decreased lymphatic-specific genes [49]. Similarly, LECs from obesity-prone mice showed decreased lymphatic markers compared to obesity-resistant animals [49]. Furthermore, not only did obese mice have impaired baseline lymphatic dysfunction, but they also exhibited heightened inflammatory responses, increased adipose deposition, and increased fibrosis in the setting of lymphatic injury compared to their lean counterparts [38]. Detmar and colleagues reported similar associations between obesity and lymphedema in mice with high-fat diet-induced obesity in which adiposity was associated with impaired collecting lymphatics [54]. This effect on 
lymphatic function was independent of lipid exposure as high-fat diet in the absence of obesity did not worsen lymphedema [55].

The relationship between obesity and lymphatic dysfunction have been demonstrated in several human studies as well. Arngrim et al. found that obese individuals have decreased adipose tissue lymphatic clearance of macromolecules when compared with lean subjects [56]. In fact, several studies have shown that some very obese patients spontaneously develop lower extremity lymphedema even without antecedent injury [57]. In a retrospective study of 51 patients with lower extremity swelling, patients with a body mass index (BMI) $\geq 30 \mathrm{~kg} / \mathrm{m}^{2}$ were more likely to have abnormal lymphoscintigrams findings as compared with patients with a BMI $<30 \mathrm{~kg} / \mathrm{m}^{2}$ [58]. In this study, a threshold BMI of $50 \mathrm{~kg} / \mathrm{m}^{2}$ was identified as predictive of an abnormal lymphoscintigram result [58]. The mechanism of obesity-induced lymphatic dysfunction is not well understood; one possibility is that increased lymphatic fluid in an enlarging limb overwhelms the draininage capacity of the existing lymphatic system. However, evidence from animal studies supports the hypothesis that obesity-induced lymphatic injury is more than just overflooding of the lymphatic system from increased lymph. Additional cellular mechanism likely play a role. Indeed, obesity in mouse models results in a perilymphatic accumulation of inflammatory cells. These inflammatory cells likely contribute to the pathology of obesity-induced lymphatic dysfunction since inhibition of inflammatory reactions with topical IL-2 inhibitors or genetic deficiency of CD4+ T cells decreased the severity of lymphatic injury in obese animals [59]. Given the link between obesity and lymphedema, several clinical trials have investigated the potential therapeutic benefit of weight loss on breast cancer-related lymphedema and have reported mixed results. While a pilot clinical trial of 21 patients showed significant differences in limb volume with weight loss, larger trials, including the PAL and WISER trials, failed to replicate these findings [60-62]. However, both the PAL and WISER trials had a follow-up time of 1 year, which may not be sufficient time to observe the true effects of weight loss given the chronic course of lymphedema. Differences in follow-up time, method of limb volume measurements, and sample size likely contributed to differences in these studies, and additional investigations into the long-term effects of weight loss on lymphedema is warranted.

\section{Lymphedema Is Associated with Recurrent Infections}

About a third of patients with lymphedema develop recurrent soft tissue infections [63,64]. These infections often require hospitalization for intravenous antibiotics and can be severe in some cases $[63,65]$. Indeed, some patients require lifelong suppressive antibiotic therapy and develop infections despite these treatments. Often, infections lead to increasing severity of lymphedema, suggesting that infections can injure the lymphatic system [66]. In some patients, infections are cited as a cause of secondary lymphedema, suggesting a direct role of bacteria in generating lymphatic dysfunction $[67,68]$. This concept is supported by a recent study demonstrating the interplay between bacteria and the lymphatic system on a molecular level. Jones et al. showed that when mice are locally inoculated with Methicillin-resistant Staphylococcus aureus (MRSA) in the hindlimb, they developed lymphatic dysfunction that was sustained even after the infection and inflammation had resolved [69]. Lymphatic dysfunction in these animals was associated with the loss of lymphatic muscle cells (LMCs), a critical component for lymphatic contraction [69]. In vitro experiments using MRSA-conditioned media showed that bacterial products can cause LMC death [69]. The causative agents for this injury were noted to be exotoxins controlled by gene regulator agr; notably, infection with agr mutant MRSA did not reduce lymphatic function or cause LMC injury [69].

Interestingly, several studies also demonstrated the detrimental effects of lymphatic dysfunction on host humoral and innate immunity as well as peripheral tolerance. The accumulation of T-regulatory cells (Tregs) at sites distal to lymphatic injury impairs bacterial phagocytosis, DC activation, antibody production, and T-cell mediated inflammation in response to lymphatic injury [70]. Depletion of Tregs restored these immunologic responses [70]. Conversely, Tregs also play a role in suppressing the hallmark inflammatory response necessary for the development of lymphedema; transgenic 
mice with an inducible form of Treg depletion sustained worsening edema associated with increased inflammatory infiltrate [71]. Not surprisingly, increased infiltration of Tregs has been seen in both mouse and human lymphedematous tissues [70,71]. These findings suggest dual roles of Tregs in lymphedema that involve dampening of the inflammatory response that contributes to lymphatic dysfunction as well as dampening of the host humoral and innate immunity.

Additional impairments in host immunity have been reported in both obese and transgenic mice with primary lymphatic dysfunction. In mice with obesity-induced lymphatic dysfunction, heightened dermatitis was seen in response to inflammatory skin stimuli that was reversible with treatment to promote lymphangiogenesis [38]. Similar alterations in peripheral tolerance were noted in K14-VEGFR-3-Ig mice that lack dermal lymphatics; these animals demonstrated robust contact hypersensitivity that became pathologic at 1 year when signs of autoimmunity became apparent [72]. K14-VEGFR-3-Ig mice were also found to have decreased antibody titers in response to dermal immunization, a phenomenon attributed to impaired antigen transport and DC trafficking that was seen in these animals, since B cells isolated from transgenic mice demonstrated similar functionality compared to those of WT mice [72]. Similarly, in an inducible mouse mode of local lymphatic ablation, lymph node transplant improved lymphedema as well as DC trafficking and the adaptive immune response [73]. Taken together, these results suggest an interconnected role of the lymphatics system and infection in which microorganisms contain innate mechanisms to damage host lymphatics; at the same time, lymphatic dysfunction can impair the host immune response.

\section{Future Directions and Conclusion}

Lymphedema is a chronic, debilitating, and currently incurable disease. The delayed presentation and variable natural history of lymphedema along with the observation that disease development is only seen in a subset of patients with lymphatic injury suggests additional pathologic events are necessary to tip the balance against effective lymphangiogenesis. Recent evidence suggests inflammation, fibrosis, adipose deposition, and even infectious etiologies in the setting of initial lymphatic insult is responsible for maintaining the vicious cycle of lymphatic dysfunction. Investigations into the molecular underpinnings of how lymphedema contributes to these pathologic features and vice versa suggests new strategies aimed at disease prevention and treatment. To this aim, animal studies have contributed significantly to a greater understanding of the pathogenesis of lymphedema and its pathologic findings. However, no animal model is perfect, and each has its limitations. The tail surgery and PLND mouse models of lymphedema are commonly used, however both represent acute models of lymphedema that spontaneously resolve over time with little fibrosis or adipose deposition. Our laboratory recently reported a new mouse model with an inducible mechanism of non-surgical LEC ablation, resulting in chronic and progressive edema with similar histologic and radiographic features as seen in the human disease [74]. Concurrent analysis with clinical specimens in addition to the utilization of various mouse models corroborates and strengthens the findings of preclinical studies. Indeed, several surgical and pharmacologic modalities to treat lymphedema have been tested as a result of animal studies such as lymph node transplant, stem cell therapy, and drugs to target inflammation (ketoprofen, ubenimex) and to promote lymphangiogenesis $[75,76]$.

Alitalo and colleagues first tested adenovirally delivered VEGF-C in mouse models of lymphedema in which the axillary lymph node was surgically excised [77]. In these animals, short-term treatment with VEGF-C resulted in leaky lymphatics at 2 weeks without improvements in drainage. These leaky vessels were associated with a discontinuous pattern of adherens and tight junction proteins as well as non-functioning valves [77]. However, by 6 months, collecting lymphatic leakiness decreased with concomitant increased uniformity of endothelial junctions, functionality of vessel valves, and improved drainage [77]. Despite successful regeneration of collecting lymphatic vessels, lymph node regeneration did not occur [77]. To accomplish this, VEGF-C therapy was combined with lymph node transplantation, which resulted in increased incorporation of transplants into the existing lymphatic vasculature and improved drainage compared to control animals [77]. Of note, VEGF-C 
is upregulated in lymphedematous tissue, suggesting that the formation of collateral lymphatic vasculature is inhibited in this setting [78]. The exact mechanism for this phenomenon requires additional investigation but may be attributed to the persistence of fibrotic tissue at the zone of injury or lack of normal lymphatic vessel anatomy; consequently, it is possible that the combination of VEGF-C treatment with lymph node transplantation is necessary for the development of functional collateral lymphatic circulation. The therapeutic benefit of combined VEGF-C and lymph node transplant was additionally shown in a porcine mode of lymphedema [79]. These animal studies led to the patent of AdAptVEGF-C Adenoviral Vector, which is currently under active clinical testing [80].

Our understanding of the role of fibrosis, adipogenesis, and bacterial infections in the pathogenesis of lymphedema is still yet emerging and there remains a gap in clinical translation. However, discovery of the inflammatory nature of lymphedema has led to the clinical testing of various anti-inflammatory drugs, albeit with varying success. Ketoprofen, a nonsteroidal anti-inflammatory drug, showed promise in the mouse model of lymphedema in which treatment improved swelling and histopathologic changes seen in lymphedematous animals compared to controls [81]. However, in an open-label clinical trial, there was no difference between ketoprofen and placebo in regards to limb volume, although there were improvements in skin thickness and histopathology in the ketoprofen treatment arm [76]. Subsequent preclinical studies showed that the mechanism of ketoprofen's therapeutic effect on lymphedema was due to its inhibition of the 5-lipoxygenase metabolite leukotriene $\mathrm{B}_{4}\left(\mathrm{LTB}_{4}\right)$ [75]. Antagonism of $\mathrm{LTB}_{4}$ improved lymphedema by improving lymphatic function and restoring lymphatic networks in the mouse tail model of lymphedema [75]. These findings led to the clinical testing of ubenimex, a protease inhibitor that antagonizes the biosynthesis of $\mathrm{LTB}_{4}$, among several other targets. Unfortunately, ubenimex also failed to demonstrate improvements in limb volume in a phase 2 clinical trial [82]. Our laboratory has found that topical tacrolimus, a T-cell immunosuppressive drug, decreases lymphedema in association with decreased T-cell infiltration and tissue fibrosis without systemic absorption in the mouse tail model of lymphedema; this drug may hold promise for future clinical trials [83].

The pathogenesis of secondary lymphedema has proven to be more complex than simple lymphatic injury. Common pathologic features seen in lymphedema are not mere manifestations of the disease but also contribute to its pathogenesis. These molecular interactions between lymphedema and its various pathologic findings represent potential vulnerabilities for which new pharmeutical therapies may be developed.

Funding: Salary support for C.Y.L. was provided by the NIH T32 CA009501 grant.

Conflicts of Interest: The authors declare no conflict of interest.

\section{Abbreviations}

$\begin{array}{ll}\text { CDT } & \text { complete decongestive therapy } \\ \text { ISL } & \text { International Society of Lymphology } \\ \text { PLND } & \text { popliteal lymph node dissection } \\ \text { WT } & \text { wild-type } \\ \text { VEGF-C } & \text { vascular endothelial growth factor C } \\ \text { DC } & \text { dendritic cell } \\ \text { iNOS } & \text { inducible nitric oxide synthase } \\ \text { LEC } & \text { lymphatic endothelial cell } \\ \text { Th1 } & \text { T helper } 1 \\ \text { Th2 } & \text { T helper } 2 \\ \text { TGF- } \beta 1 & \text { transforming growth factor- } \beta 1 \\ \text { BMI } & \text { body mass index } \\ \text { MRSA } & \text { Methicillin-resistant Staphylococcus aureus } \\ \text { LMC } & \text { lymphatic muscle cell } \\ \text { Treg } & \text { T-regulatory cell } \\ \text { LTB } 4 & \text { leukotriene } B_{4}\end{array}$




\section{References}

1. Szuba, A.; Rockson, S.G. Lymphedema: Anatomy, physiology and pathogenesis. Vasc. Med. 1997, 2, 321-326. [CrossRef] [PubMed]

2. McLaughlin, S.A.; Wright, M.J.; Morris, K.T.; Giron, G.L.; Sampson, M.R.; Brockway, J.P.; Hurley, K.E.; Riedel, E.R.; Van Zee, K.J. Prevalence of lymphedema in women with breast cancer 5 years after sentinel lymph node biopsy or axillary dissection: Objective measurements. J. Clin. Oncol. Off. J. Am. Soc. Clin. Oncol. 2008, 26, 5213-5219. [CrossRef] [PubMed]

3. Armer, J.M.; Fu, M.R.; Wainstock, J.M.; Zagar, E.; Jacobs, L.K. Lymphedema following breast cancer treatment, including sentinel lymph node biopsy. Lymphology 2004, 37, 73-91. [CrossRef] [PubMed]

4. Kwan, M.L.; Darbinian, J.; Schmitz, K.H.; Citron, R.; Partee, P.; Kutner, S.E.; Kushi, L.H. Risk factors for lymphedema in a prospective breast cancer survivorship study: The pathways study. Arch. Surg. 2010, 145, 1055-1063. [CrossRef] [PubMed]

5. Todo, Y.; Yamamoto, R.; Minobe, S.; Suzuki, Y.; Takeshi, U.; Nakatani, M.; Aoyagi, Y.; Ohba, Y.; Okamoto, K.; Kato, H. Risk factors for postoperative lower-extremity lymphedema in endometrial cancer survivors who had treatment including lymphadenectomy. Gynecol. Oncol. 2010, 119, 60-64. [CrossRef] [PubMed]

6. Norman, S.A.; Localio, A.R.; Kallan, M.J.; Weber, A.L.; Torpey, H.A.; Potashnik, S.L.; Miller, L.T.; Fox, K.R.; DeMichele, A.; Solin, L.J. Risk factors for lymphedema after breast cancer treatment. Cancer Epidemiol. Biomark. Prev. 2010, 19, 2734-2746. [CrossRef] [PubMed]

7. Starritt, E.C.; Joseph, D.; McKinnon, J.G.; Lo, S.K.; De Wilt, J.H.; Thompson, J.F. Lymphedema after complete axillary node dissection for melanoma: Assessment using a new, objective definition. Ann. Surg. 2004, 240, 866-874. [CrossRef]

8. Gross, J.P.; Whelan, T.J.; Parulekar, W.R.; Chen, B.E.; Rademaker, A.W.; Helenowski, I.B.; Donnelly, E.D.; Strauss, J.B. Development and validation of a nomogram to predict lymphedema after axillary surgery and radiation therapy in women with breast cancer from the NCIC CTG MA.20 randomized trial. Int. J. Radiat. Oncol. Biol. Phys. 2019, 105, 165-173. [CrossRef]

9. Bevilacqua, J.L.; Kattan, M.W.; Changhong, Y.; Koifman, S.; Mattos, I.E.; Koifman, R.J.; Bergmann, A. Nomograms for predicting the risk of arm lymphedema after axillary dissection in breast cancer. Ann. Surg. Oncol. 2012, 19, 2580-2589. [CrossRef]

10. Cormier, J.N.; Askew, R.L.; Mungovan, K.S.; Xing, Y.; Ross, M.I.; Armer, J.M. Lymphedema beyond breast cancer: A systematic review and meta-analysis of cancer-related secondary lymphedema. Cancer 2010, 116, 5138-5149. [CrossRef]

11. Brayton, K.M.; Hirsch, A.T.; Patricia, J.O.; Brien, A.C.; Karaca-Mandic, P.; Rockson, S.G. Lymphedema prevalence and treatment benefits in cancer: Impact of a therapeutic intervention on health outcomes and costs. PLoS ONE 2014, 9, e114597. [CrossRef] [PubMed]

12. Uzkeser, H.; Karatay, S.; Erdemci, B.; Koc, M.; Senel, K. Efficacy of manual lymphatic drainage and intermittent pneumatic compression pump use in the treatment of lymphedema after mastectomy: A randomized controlled trial. Breast Cancer 2015, 22, 300-307. [CrossRef] [PubMed]

13. Liao, S.F.; Huang, M.S.; Li, S.H.; Chen, I.R.; Wei, T.S.; Kuo, S.J.; Chen, S.T.; Hsu, J.C. Complex decongestive physiotherapy for patients with chronic cancer-associated lymphedema. J. Formos. Med. Assoc. 2004, 103, 344-348. [PubMed]

14. Szuba, A.; Cooke, J.P.; Yousuf, S.; Rockson, S.G. Decongestive lymphatic therapy for patients with cancer-related or primary lymphedema. Am. J. Med. 2000, 109, 296-300. [CrossRef]

15. Foldi, E. The treatment of lymphedema. Cancer 1998, 83, 2833-2834. [CrossRef]

16. McLaughlin, S.A.; DeSnyder, S.M.; Klimberg, S.; Alatriste, M.; Boccardo, F.; Smith, M.L.; Staley, A.C.; Thiruchelvam, P.T.; Hutchison, N.A.; Mendez, J.; et al. Considerations for clinicians in the diagnosis, prevention, and treatment of breast cancer-related lymphedema, recommendations from an expert panel: Part 2: Preventive and therapeutic options. Ann. Surg. Oncol. 2017, 24, 2827-2835. [CrossRef]

17. Bozkurt, M.; Palmer, L.J.; Guo, Y. Effectiveness of decongestive lymphatic therapy in patients with lymphedema resulting from breast cancer treatment regardless of previous lymphedema treatment. Breast J. 2017, 23, 154-158. [CrossRef] 
18. Garza, R., 3rd; Skoracki, R.; Hock, K.; Povoski, S.P. A comprehensive overview on the surgical management of secondary lymphedema of the upper and lower extremities related to prior oncologic therapies. BMC Cancer 2017, 17, 468. [CrossRef]

19. Granzow, J.W.; Soderberg, J.M.; Kaji, A.H.; Dauphine, C. An effective system of surgical treatment of lymphedema. Ann. Surg. Oncol. 2014, 21, 1189-1194. [CrossRef]

20. Winters, H.; Tielemans, H.J.; Hameeteman, M.; Paulus, V.A.; Beurskens, C.H.; Slater, N.J.; Ulrich, D.J. The efficacy of lymphaticovenular anastomosis in breast cancer-related lymphedema. Breast Cancer Res. Treat. 2017, 165, 321-327. [CrossRef]

21. Abu-Rustum, N.R.; Alektiar, K.; Iasonos, A.; Lev, G.; Sonoda, Y.; Aghajanian, C.; Chi, D.S.; Barakat, R.R. The incidence of symptomatic lower-extremity lymphedema following treatment of uterine corpus malignancies: A 12-year experience at memorial sloan-kettering cancer center. Gynecol. Oncol. 2006, 103, 714-718. [CrossRef] [PubMed]

22. Ryan, M.; Stainton, M.C.; Slaytor, E.K.; Jaconelli, C.; Watts, S.; MacKenzie, P. Aetiology and prevalence of lower limb lymphoedema following treatment for gynaecological cancer. Aust. N. Z. J. Obstet. Gynaecol. 2003, 43, 148-151. [CrossRef] [PubMed]

23. Grada, A.A.; Phillips, T.J. Lymphedema: Pathophysiology and clinical manifestations. J. Am. Acad. Dermatol. 2017, 77, 1009-1020.

24. Sharma, A.; Schwartz, R.A. Stewart-Treves syndrome: Pathogenesis and management. J. Am. Acad. Dermatol. 2012, 67, 1342-1348. [CrossRef] [PubMed]

25. Zampell, J.C.; Yan, A.; Elhadad, S.; Avraham, T.; Weitman, E.; Mehrara, B.J. CD4(+) cells regulate fibrosis and lymphangiogenesis in response to lymphatic fluid stasis. PLoS ONE 2012, 7, e49940. [CrossRef] [PubMed]

26. Avraham, T.; Zampell, J.C.; Yan, A.; Elhadad, S.; Weitman, E.S.; Rockson, S.G.; Bromberg, J.; Mehrara, B.J. Th2 differentiation is necessary for soft tissue fibrosis and lymphatic dysfunction resulting from lymphedema. FASEB J. 2013, 27, 1114-1126. [CrossRef] [PubMed]

27. Gousopoulos, E.; Proulx, S.T.; Scholl, J.; Uecker, M.; Detmar, M. prominent lymphatic vessel hyperplasia with progressive dysfunction and distinct immune cell infiltration in lymphedema. Am. J. Pathol. 2016, 186, 2193-2203. [CrossRef]

28. Ogata, F.; Fujiu, K.; Matsumoto, S.; Nakayama, Y.; Shibata, M.; Oike, Y.; Koshima, I.; Watabe, T.; Nagai, R.; Manabe, I. Excess lymphangiogenesis cooperatively induced by macrophages and CD4(+) T cells drives the pathogenesis of lymphedema. J. Investig. Dermatol. 2016, 136, 706-714. [CrossRef]

29. Nores, G.D.; Ly, C.L.; Cuzzone, D.A.; Kataru, R.P.; Hespe, G.E.; Torrisi, J.S.; Huang, J.J.; Gardenier, J.C.; Savetsky, I.L.; Nitti, M.D.; et al. CD4(+) T cells are activated in regional lymph nodes and migrate to skin to initiate lymphedema. Nat. Commun. 2018, 9, 1970. [CrossRef]

30. Ly, C.L.; Cuzzone, D.A.; Kataru, R.P.; Mehrara, B.J. Small numbers of CD4+ T cells can induce development of lymphedema. Plast. Reconstr. Surg. 2019, 143, 518e-526e. [CrossRef]

31. Scallan, P.J.; Davis, M.J. Genetic removal of basal nitric oxide enhances contractile activity in isolated murine collecting lymphatic vessels. J. Physiol. 2013, 591, 2139-2156. [CrossRef] [PubMed]

32. Liao, S.; Cheng, G.; Conner, D.A.; Huang, Y.; Kucherlapati, R.S.; Munn, L.L.; Ruddle, N.H.; Jain, R.K.; Fukumura, D.; Padera, T.P. Impaired lymphatic contraction associated with immunosuppression. Proc. Natl. Acad. Sci. USA 2011, 108, 18784-18789. [CrossRef] [PubMed]

33. Suami, H.; Pan, W.R.; Taylor, G.I. Changes in the lymph structure of the upper limb after axillary dissection: Radiographic and anatomical study in a human cadaver. Plast. Reconstr. Surg. 2007, 120, 982-991. [CrossRef] [PubMed]

34. Clavin, N.W.; Avraham, T.; Fernandez, J.; Daluvoy, S.V.; Soares, M.A.; Chaudhry, A.; Mehrara, B.J. TGF-beta1 is a negative regulator of lymphatic regeneration during wound repair. Am. J. Physiol. Heart Circ. Physiol. 2008, 295, H2113-H2127. [CrossRef]

35. Avraham, T.; Clavin, N.W.; Daluvoy, S.V.; Fernandez, J.; Soares, M.A.; Cordeiro, A.P.; Mehrara, B.J. Fibrosis is a key inhibitor of lymphatic regeneration. Plast. Reconstr. Surg. 2009, 124, 438-450. [CrossRef]

36. Wynn, T.A. Fibrotic disease and the $\mathrm{T}(\mathrm{H}) 1 / \mathrm{T}(\mathrm{H}) 2$ paradigm. Nat. Rev. Immunol. 2004, 4, 583-594. [CrossRef]

37. Ly, C.L.; Nores, G.D.; Kataru, R.P.; Mehrara, B.J. T helper 2 differentiation is necessary for development of lymphedema. Transl. Res. 2019, 206, 57-70. [CrossRef] 
38. Savetsky, I.L.; Torrisi, J.S.; Cuzzone, D.A.; Ghanta, S.; Albano, N.J.; Gardenier, J.C.; Joseph, W.J.; Mehrara, B.J. Obesity increases inflammation and impairs lymphatic function in a mouse model of lymphedema. Am. J. Physiol. Heart Circ. Physiol. 2014, 307, H165-H172. [CrossRef]

39. Shin, K.; Kataru, R.P.; Park, H.J.; Kwon, B.I.; Kim, T.W.; Hong, Y.K.; Lee, S.H. TH2 cells and their cytokines regulate formation and function of lymphatic vessels. Nat. Commun. 2015, 6, 6196. [CrossRef]

40. Savetsky, I.L.; Ghanta, S.; Gardenier, J.C.; Torrisi, J.S.; Nores, G.D.; Hespe, G.E.; Nitti, M.D.; Kataru, R.P.; Mehrara, B.J. Th2 cytokines inhibit lymphangiogenesis. PLoS ONE 2015, 10, e0126908. [CrossRef]

41. Wynn, T.A. Cellular and molecular mechanisms of fibrosis. J. Pathol. 2008, 214, 199-210. [CrossRef] [PubMed]

42. Avraham, T.; Daluvoy, S.; Zampell, J.; Yan, A.; Haviv, Y.S.; Rockson, S.G.; Mehrara, B.J. Blockade of transforming growth factor-beta1 accelerates lymphatic regeneration during wound repair. Am. J. Pathol. 2010, 177, 3202-3214. [CrossRef] [PubMed]

43. Di, S.; Ziyou, Y.; Liu, N.F. Pathological changes of lymphedematous skin: increased mast cells, related proteases, and activated transforming growth factor-beta1. Lymphat. Res. Biol. 2016, 14, 162-171. [CrossRef] [PubMed]

44. Gieseck, R.L.; Wilson, M.S., 3rd; Wynn, T.A. Type 2 immunity in tissue repair and fibrosis. Nat. Rev. Immunol. 2018, 18, 62-76. [CrossRef]

45. Narushima, M.; Yamamoto, T.; Ogata, F.; Yoshimatsu, H.; Mihara, M.; Koshima, I. Indocyanine green lymphography findings in limb lymphedema. J. Reconstr. Microsurg. 2016, 32, 72-79.

46. Sosa-Pineda, B.; Wigle, J.T.; Oliver, G. Hepatocyte migration during liver development requires Prox1. Nat. Genet. 2000, 25, 254-255. [CrossRef]

47. Escobedo, N.; Proulx, S.T.; Karaman, S.; Dillard, M.E.; Johnson, N.; Detmar, M.; Oliver, G. Restoration of lymphatic function rescues obesity in Prox1-haploinsufficient mice. JCI insight 2016, 1, e85096. [CrossRef]

48. Harvey, N.L.; Srinivasan, R.S.; Dillard, M.E.; Johnson, N.C.; Witte, M.H.; Boyd, K.; Sleeman, M.W.; Oliver, G. Lymphatic vascular defects promoted by Prox1 haploinsufficiency cause adult-onset obesity. Nat. Genet. 2005, 37, 1072-1081. [CrossRef]

49. Nores, G.G.; Cuzzone, D.A.; Albano, N.J.; Hespe, G.E.; Kataru, R.P.; Torrisi, J.S.; Gardenier, J.C.; Savetsky, I.L.; Aschen, S.Z.; Nitti, M.D.; et al. Obesity but not high-fat diet impairs lymphatic function. Int. J. Obes. 2016, 40, 1582-1590. [CrossRef]

50. Aschen, S.; Zampell, J.C.; Elhadad, S.; Weitman, E.; Andrade, M.D.; Mehrara, B.J. Regulation of adipogenesis by lymphatic fluid stasis: Part II. Expression of adipose differentiation genes. Plast. Reconstr. Surg. 2012, 129, 838-847. [CrossRef]

51. Zampell, J.C.; Aschen, S.; Weitman, E.S.; Yan, A.; Elhadad, S.; Andrade, M.D.; Mehrara, B.J. Regulation of adipogenesis by lymphatic fluid stasis: Part I. Adipogenesis, fibrosis, and inflammation. Plast. Reconstr. Surg. 2012, 129, 825-834. [CrossRef] [PubMed]

52. Cuzzone, D.A.; Weitman, E.S.; Albano, N.J.; Ghanta, S.; Savetsky, I.L.; Gardenier, J.C.; Joseph, W.J.; Torrisi, J.S.; Bromberg, J.F.; Olszewski, W.L.; et al. IL-6 regulates adipose deposition and homeostasis in lymphedema. Am. J. Physiol. Heart Circ. Physiol. 2014, 306, H1426-H1434. [CrossRef] [PubMed]

53. Werner, R.S.; McCormick, B.; Petrek, J.; Cox, L.; Cirrincione, C.; Gray, J.R.; Yahalom, J. Arm edema in conservatively managed breast cancer: Obesity is a major predictive factor. Radiology 1991, 180, 177-184. [CrossRef] [PubMed]

54. Blum, K.S.; Karaman, S.; Proulx, S.T.; Ochsenbein, A.M.; Luciani, P.; Leroux, J.C.; Wolfrum, C.; Detmar, M. Chronic high-fat diet impairs collecting lymphatic vessel function in mice. PLoS ONE 2014, 9, e94713. [CrossRef]

55. Gousopoulos, E.; Karaman, S.; Proulx, S.T.; Leu, K.; Buschle, D.; Detmar, M. High-fat diet in the absence of obesity does not aggravate surgically induced lymphoedema in mice. Eur. Surg. Res. 2017, 58, 180-192. [CrossRef]

56. Arngrim, N.; Simonsen, L.; Holst, J.J.; Bülow, J. Reduced adipose tissue lymphatic drainage of macromolecules in obese subjects: A possible link between obesity and local tissue inflammation? Int. J. Obes. (London) 2013, 37, 748-750. [CrossRef]

57. Szuba, A.; Shin, W.S.; Strauss, H.W.; Rockson, S. The third circulation: Radionuclide lymphoscintigraphy in the evaluation of lymphedema. J. Nucl. Med. 2003, 44, 43-57.

58. Greene, A.K.; Grant, F.D.; Slavin, S.A.; Maclellan, R.A. Obesity-induced lymphedema: Clinical and lymphoscintigraphic features. Plast. Reconstr. Surg. 2015, 135, 1715-1719. [CrossRef] 
59. Torrisi, J.S.; Hespe, G.E.; Cuzzone, D.A.; Savetsky, I.L.; Nitti, M.D.; Gardenier, J.C.; Nores, G.D.; Jowhar, D.; Kataru, R.P.; Mehrara, B.J. Inhibition of inflammation and iNOS improves lymphatic function in obesity. Sci. Rep. 2016, 6, 19817. [CrossRef]

60. Schmitz, K.H.; Troxel, A.B.; Dean, L.T.; DeMichele, A.; Brown, J.C.; Sturgeon, K.; Zhang, Z.; Evangelisti, M.; Spinelli, B.; Kallan, M.J.; et al. Effect of home-based exercise and weight loss programs on breast cancer-related lymphedema outcomes among overweight breast cancer survivors: The WISER survivor randomized clinical trial. JAMA Oncol. 2019, 5, 1605-1613. [CrossRef]

61. Schmitz, K.H.; Ahmed, R.L.; Troxel, A.; Cheville, A.; Smith, R.; Lewis-Grant, L.; Bryan, C.J.; Williams-Smith, C.T.; Greene, Q.P. Weight lifting in women with breast-cancer-related lymphedema. N. Engl. J. Med. 2009, 361, 664-673. [CrossRef] [PubMed]

62. Shaw, C.; Mortimer, P.; Judd, P.A. A randomized controlled trial of weight reduction as a treatment for breast cancer-related lymphedema. Cancer 2007, 110, 1868-1874. [CrossRef] [PubMed]

63. Moffatt, C.J.; Franks, P.J.; Doherty, D.C.; Williams, A.F.; Badger, C.; Jeffs, E.; Bosanquet, N.; Mortimer, P.S. Lymphoedema: An underestimated health problem. Qjm 2003, 96, 731-738. [CrossRef] [PubMed]

64. Ridner, S.H.; Deng, J.; Fu, M.R.; Radina, E.; Thiadens, S.R.; Weiss, J.; Dietrich, M.S.; Cormier, J.N.; Tuppo, C.M.; Armer, J.M. Symptom burden and infection occurrence among individuals with extremity lymphedema. Lymphology 2012, 45, 113-123. [PubMed]

65. Connor, P.M.; Gamelli, R. Challenges of cellulitis in a lymphedematous extremity: A case report. Cases J. 2009, 2, 9377.

66. Campanholi, L.L.; Neto, J.P.D.; Fregnani, J.H.T.G. Mathematical model to predict risk for lymphoedema after treatment of cutaneous melanoma. Int. J. Surg. 2011, 9, 306-309. [CrossRef] [PubMed]

67. Soo, J.K.; Bicanic, T.A.; Heenan, S.; Mortimer, P.S. Lymphatic abnormalities demonstrated by lymphoscintigraphy after lower limb cellulitis. Br. J. Dermatol. 2008, 158, 1350-1353. [CrossRef]

68. Valente, A.; Camacho, E.L.; Paiva, E.V. Lymphoscintigraphic evaluation in patients after erysipelas. Lymphology 2000, 33, 177-180.

69. Jones, D.; Meijer, E.F.; Blatter, C.; Liao, S.; Pereira, E.R.; Bouta, E.M.; Jung, K.; Chin, S.M.; Huang, P.; Munn, L.L.; et al. Methicillin-resistant staphylococcus aureus causes sustained collecting lymphatic vessel dysfunction. Sci. Transl. Med. 2018, 10, eaam7964. [CrossRef]

70. Nores, G.D.; Ly, C.L.; Savetsky, I.L.; Kataru, R.P.; Ghanta, S.; Hespe, G.E.; Rockson, S.G.; Mehrara, B.J. Regulatory T cells mediate local immunosuppression in lymphedema. J. Investig. Dermatol. 2018, 138, 325-335. [CrossRef]

71. Gousopoulos, E.; Proulx, S.T.; Bachmann, S.B.; Scholl, J.; Dionyssiou, D.; Demiri, E.; Halin, C.; Dieterich, L.C.; Detmar, M. Regulatory T cell transfer ameliorates lymphedema and promotes lymphatic vessel function. JCI Insight 2016, 1, e89081. [CrossRef] [PubMed]

72. Thomas, S.N.; Rutkowski, J.M.; Pasquier, M.; Kuan, E.L.; Alitalo, K.; Randolph, G.J.; Swartz, M.A. Impaired humoral immunity and tolerance in K14-VEGFR-3-Ig mice that lack dermal lymphatic drainage. J. Immunol. 2012, 189, 2181-2190. [CrossRef] [PubMed]

73. Huang, J.J.; Gardenier, J.C.; Hespe, G.E.; Nores, G.D.; Kataru, R.P.; Ly, C.L.; Martinez-Corral, I.; Ortega, S.; Mehrara, B.J. Lymph node transplantation decreases swelling and restores immune responses in a transgenic model of lymphedema. PLoS ONE 2016, 11, e0168259. [CrossRef] [PubMed]

74. Gardenier, J.C.; Hespe, G.E.; Kataru, R.P.; Savetsky, I.L.; Torrisi, J.S.; Nores, G.D.; Dayan, J.J.; Chang, D.; Zampell, J.; Martínez-Corral, I.; et al. Diphtheria toxin-mediated ablation of lymphatic endothelial cells results in progressive lymphedema. JCI Insight 2016, 1, e84095. [CrossRef] [PubMed]

75. Tian, W.; Rockson, S.G.; Jiang, X.; Kim, J.; Begaye, A.; Shuffle, E.M.; Tu, A.B.; Cribb, M.; Nepiyushchikh, Z.; Feroze, A.H.; et al. Leukotriene B4 antagonism ameliorates experimental lymphedema. Sci. Transl. Med. 2017, 9, eaal3920. [CrossRef] [PubMed]

76. Rockson, S.G.; Tian, W.; Jiang, X.; Kuznetsova, T.; Haddad, F.; Zampell, J.; Mehrara, B.; Sampson, J.P.; Roche, L.; Kim, J.; et al. Pilot studies demonstrate the potential benefits of antiinflammatory therapy in human lymphedema. JCI Insight 2018, 3, e123775. [CrossRef]

77. Tammela, T.; Saaristo, A.; Holopainen, T.; Lyytikkä, J.; Kotronen, A.; Pitkonen, M.; Abo-Ramadan, U.; Ylä-Herttuala, S.; Petrova, T.V.; Alitalo, K. Therapeutic differentiation and maturation of lymphatic vessels after lymph node dissection and transplantation. Nat. Med. 2007, 13, 1458-1466. [CrossRef] 
78. Rutkowski, J.M.; Moya, M.; Johannes, J.; Goldman, J.; Swartz, M.A. Secondary lymphedema in the mouse tail: Lymphatic hyperplasia, VEGF-C upregulation, and the protective role of MMP-9. Microvasc. Res. 2006, 72, 161-171. [CrossRef]

79. Lähteenvuo, M.; Honkonen, K.; Tervala, T.; Tammela, T.; Suominen, E.; Lähteenvuo, J.; Kholová, I.; Alitalo, K.; Ylä-Herttuala, S.; Saaristo, A. Growth factor therapy and autologous lymph node transfer in lymphedema. Circulation 2011, 123, 613-620. [CrossRef]

80. A Phase I Study with Lymfactin $® i n$ the Treatment of Patients with Secondary Lymphedema. Available online: https://ClinicalTrials.gov/show/NCT02994771 (accessed on 2 January 2020).

81. Nakamura, K.; Radhakrishnan, K.; Wong, Y.M.; Rockson, S.G. Anti-inflammatory pharmacotherapy with ketoprofen ameliorates experimental lymphatic vascular insufficiency in mice. PLoS ONE 2009, 4, e8380. [CrossRef]

82. Ubenimex in Adult Patients with Lymphedema of the Lower Limb (ULTRA). Available online: https: //ClinicalTrials.gov/show/NCT02700529 (accessed on 2 January 2020).

83. Gardenier, J.C.; Kataru, R.P.; Hespe, G.E.; Savetsky, I.L.; Torrisi, J.S.; Nores, G.D.; Jowhar, D.K.; Nitti, M.D.; Schofield, R.C.; Carlow, D.C.; et al. Topical tacrolimus for the treatment of secondary lymphedema. Nat. Commun. 2017, 8, 14345. [CrossRef] [PubMed]

(C) 2020 by the authors. Licensee MDPI, Basel, Switzerland. This article is an open access article distributed under the terms and conditions of the Creative Commons Attribution (CC BY) license (http://creativecommons.org/licenses/by/4.0/). 